\title{
$\$$ Research Square \\ Engineering students' readiness for online learning amidst the COVID-19 pandemic: Scale validation and lessons learned from a developing country
}

\section{Md. Abdullah Al Mamun ( $\nabla$ a.mamun@iut-dhaka.edu )}

Islamic University of Technology https://orcid.org/0000-0001-8490-5891

\section{Md. Akbar Hossain}

Manukau Institute of Technology

\section{Sayedus Salehin}

Islamic University of Technology

\section{Md. Shahadat Hossain Khan \\ Islamic University of Technology \\ Mahbub Hasan \\ Islamic University of Technology}

\section{Research Article}

Keywords: Online learning readiness, COVID-19 pandemic, Bangladesh, Engineering education, Structural Equation Modelling, Situational factors, Digital inequality

Posted Date: April 5th, 2021

DOI: https://doi.org/10.21203/rs.3.rs-374991/v1

License: (c) (i) This work is licensed under a Creative Commons Attribution 4.0 International License. Read Full License 


\section{Abstract}

Background - Engineering education utilizes a face-to-face model for delivery of course materials and workshops. The recent outbreak of the COVID-19 pandemic imposed a countrywide lockdown and forced education institutes to shift to an internet-based online delivery mode.

Purpose/Hypothesis - This study developed an instrument to meticulously measure the students' readiness for online learning in a pandemic situation. A situation like COVID-19 accelerates a long-standing issue of digital inequality among the students in education. The study proposed a reconceptualised model for students' online readiness for emergencies like COVID-19. The proposed model consists of (a) motivation, (b) self-efficacy, and (c) situational factors.

Design/Method - The proposed model was validated with the engineering students (for pilot study $N=68$ and main study $N=988$ ) from several universities in Bangladesh. To validate the underlying relationships between the latent constructs, an exploratory factor analysis (EFA) was performed followed by structural equation modelling (SEM) for the construct validity of the measurement model and to assess the model fit.

Results - The findings showed that besides motivation and self-efficacy, the situational factors describing the contextual dynamics emerging from the COVID-19 significantly influenced the student's online readiness.

Conclusions - The impact of situational factors on student readiness for online learning is complex, specially during events such as the COVID-19 pandemic. By analyzing the collected data, it is evident that current practices of teaching should be blended with face-to-face, synchronous and asynchronous internet-based learning. We argue that digital inequality is an important factor influencing student readiness for online learning.

\section{Introduction}

Bangladesh, being a high risk and country vulnerable to the COVID-19 pandemic (Hossain, Ferdous, \& Siddiqee, 2020; Monjur \& Hassan, 2020), took several measures to combat transmission of the virus. The most immediate measure introduced by the country was to regulate the practice of 'social distancing' (Yeasmin et al., 2020) to flatten the curve of COVID-19 transmission. As a result, all educational institutions were closed across the country. Social distancing became the 'new normal' for students and the usual comradeship of campus life disappeared. This has drastically impacted on Bangladesh's educational system, resulting in a loss of learning opportunities. Roughly 3.7 million students and a million teachers in the higher education sector are reportedly now stuck at home (Ahmed, 2020b). The disruption and interruptions to the education system in Bangladesh caused by COVID-19 creates both immediate and long-term effects. One such long-term and serious effect is thought to be an economic downturn (Ahmed, 2020a). Specifically, the disruption of engineering education has the potential to push Bangladesh further down comparative economic growth and development tables. Since engineering education is considered to be a key factor for the developing economy of Bangladesh (Chowdhury \& Alam, 2012), closing all the engineering universities across the country poses a serious threat to the nation's economic progress.

To minimize interruption caused by the COVID-19 pandemic, engineering universities in Bangladesh acted quickly to shift all face-to-face lectures to a home-based online distance learning mode using learning platforms such as Google classroom, Moodle, Canvas, Blackboard, Zoom, Microsoft Teams, and similar other web applications. This paradigm shift from face-to-face learning to online distance mode creates two major complexities. Firstly, academic matters such as delivery, teachers' expertise, student preparedness, and engagement within this new virtual learning space must all be addressed (Peters et al., 2020). The second issue, perhaps more sensitive, relates to the physical and psychological wellbeing of the students. The absence of social and physical interaction has adverse effects on students' wellbeing (Twenge, Spitzberg, \& Campbell, 2019). Research shows that the COVID-19 pandemic generates fear among people, 
leading to depression, stress, anxiety and other psychological and mental health issues (Sakib et al., 2020). This raises a genuine concern among educators about the students' readiness for online learning and whether meaningful learning can occur in an online environment. Nevertheless, engineering universities are continuing to shift course delivery to fullyfledged online learning environments as no other viable solutions are available. Students get little time to cope with this 'new normal' in their educational lives.

Therefore, an important question requires immediate attention: To what extent are the engineering students of Bangladesh ready for the online classes that are replacing face-to-face learning during the COVID-19 pandemic? Because the event is unique, research into understanding student readiness for online learning in a pandemic situation is only starting to emerge, and no reported research has been found in the context of engineering education in Bangladesh. Though a number of studies attempted to measure students' readiness for online learning (Arthur-Nyarko, Agyei, \& Armah, 2020b; Doe, Castillo, \& Musyoka, 2017; Yu, 2018), none of them fully address the factors relating to an emergency situation. Chung, Subramaniam, and Dass (2020) measured students' online learning readiness amidst the COVID-19 pandemic, nonetheless, they did not address the situational and context specific factors that emerged due to the pandemic. Thus, a careful understanding of the current pandemic situation and a reconceptualisation of the dimensions and constructs of the students' readiness for online learning is warranted.

For this reason, the current study develops and validates a more specific instrument that can be used to measure the students' readiness for online learning in a pandemic situation. Secondly, this study investigates how demographic factors influence the online learning readiness of engineering students of Bangladesh during the pandemic. Thus, this study sought to answer the following two questions in the context of the current pandemic caused by COVID-19:

1. What is the reliability, validity, and model fit evidence of the survey scale to assess engineering students' readiness for online learning?

2. To what extent are engineering students of Bangladesh (in terms of gender, level of study, place of living, and university type) ready to learn in online environments?

\section{Reconceptualising The Constructs Of Students' Online Readiness In The Pandemic Situation}

\subsection{Motivation and self-efficacy: Two key constructs of students' online readiness}

COVID-19 brings an unprecedented situation that demands rapid measures to meet the urgency of online course delivery by educational institutions. Therefore, renewed attention is warranted to reconceptualise the students' readiness for online learning in such a pressing situation. In previous literature, motivation was identified as the most crucial construct of students' readiness for online learning (Chung et al., 2020; Xiong, So, \& Toh, 2015; Yu, 2018). In the current pandemic situation, this has similarly become the primary factor for students to engage successfully in remote learning. The absence of social structure, close interactions, easy access to teachers and peers in online learning during COVID19 pandemic may influence students' readiness to learn in this manner (Allam, Hassan, Sultan, Mohideen, \& Kamal, 2020). However, the key factor that can help students to maintain their internal drive towards effective participation in online learning is their self-motivational force. Thus, more than ever before, motivational construct remains the mainstay of students' readiness for online learning during the pandemic.

COVID-19 also requires students to become heavily dependent on technology for their learning and to develop digital competency. Early literature refers to 'self-efficacy' as aspects which help students benefit from technology and its environment. Digital readiness or self-efficacy requires students to have knowledge of and competencies in using 
modern technologies to achieve the educational objectives determined by their academic institutions (Hong \& Kim, 2018). Digital competency is the most essential skill which aligns with the learning readiness dimension in contemporary online settings (Hung, Chou, Chen, \& Own, 2010). The pandemic makes it vital for students to equip themselves with computer/internet literacy for successful online participation (Allam et al., 2020). As a result, students' self-efficacy to use technology for online learning also appeared as a crucial construct to measure students' readiness.

\subsection{Situational factors: The emerging constructs for students' online readiness}

With social distancing measures in place due to COVID-19, technologies become the backbone of education. This accelerates a long-standing issue of 'digital inequality' among students in education. Advantaged groups always benefit by being able to readily scale up their use of modern technologies through apps and services (Khilnani, Schulz, \& Robinson, 2020). In contrast, students from low socio-economic countries will prosper less in life due to a shortage of digital resources. Stress resulting from disrupted education and increased dependency on technology suggests that COVID-19 will increase existing digital inequalities (Beaunoyer, Dupéré, \& Guitton, 2020). In their study, Miglani and Awadhiya (2017) pointed out that the availability of digital resources and the ability to use and benefit from these are the key factors that characterize digital inequality. Beaunoyer et al. (2020) further state: "digital inequality is the degree to which individuals have the capacity, knowledge, motivation, and competence to access, process, engage and understand the information needed to obtain benefits from the use of digital technologies" (p. 1).

Based on the notion of digital inequality accelerated by the COVID-19 pandemic, several key dimensions with increased relevancy to students' readiness for online learning become apparent. In this study, we identified these dimensions under a common construct named "situational factors". The first factor we conceptualise is the availability and access to the digital resources amidst a pandemic situation. Second is the 'learning atmosphere' in the home environment - a unique and unprecedented context emerging because of COVID-19 lockdown. Third is the role of educational institutions that can accelerate students' online learning by providing support in terms of equipment, stable network connection and other necessary logistics.

Ensuring digital access or availability of appropriate technologies for students is a fundamental challenge for online learning in a country like Bangladesh. Technology and Internet use was never a priority in the education system of Bangladesh in the pre COVID-19 era and virtual classrooms added a further challenge. However, like every other country, the status of virtual classrooms has shifted from an 'amenity to a necessity' to maintain educational progress during the pandemic (Beaunoyer et al., 2020). Research shows that low-income families are suffering the most from the COVID-19 economic crisis because they have fewer and lower quality digital appliances (Fernandes, 2020; Wang \& Tang, 2020). Bangladesh is not an exception here. Due to their low socio-economic status, many students in Bangladesh do not have the modern devices to readily adjust to the technology based 'new normal' life. Instead, research shows that use of outdated devices, as is the supposed case for the majority students of Bangladesh, results in delays in connecting to online resources and an overall less satisfying experience (Beaunoyer et al., 2020). Also, the increased cost of internet data and poor connectivity remains a serious threat for technology adoption in developing countries (ITU, 2017). As a result, students get fewer opportunities to access, engage with, and experience modern technologies.

Digital inequality is not only concerned with technology and its effective use, but also, for example, spaces that offer an appropriate learning atmosphere (Beaunoyer et al., 2020). There is no question that the COVID-19 pandemic triggers environmental and situation specific difficulties for students to learn at home. These difficulties can reduce students' 
ability to concentrate on the learning resources, create challenges to engage with the online classes, and hamper active and meaningful discussions between peers and teachers (Neuwirth, Jović, \& Mukherji, 2020). In fact, Neuwirth et al. (2020) reasoned that some issues are exacerbated by underlying conditions of disparity of available resources triggered by the COVID-19 pandemic. These include the lack of a calm and peaceful study space within the home environment which can help students to learn in comfort and with privacy. However, a positive learning atmosphere is not simply silence: it is a complex-to-describe combination of sense experience and feelings shaped by underlying spatial organization, structures, social rules and interactions governed by the environment (Cox, 2017). Often too, close proximities with other family members trigger disturbances, and students can be reluctant to use a webcam during classes which may expose their socioeconomic and living conditions (Neuwirth et al., 2020). Students in such a complex environment are also emotionally charged: there is a sense of belonging but also feelings of anxiety (Cox, 2017). This situational specific factor therefore signifies the importance of students' psychological preparedness for online learning. In brief, the learning atmosphere is a crucial ingredient to stimulate student motivation (Pamungkas, 2019). Ryan and Deci (2000) argue that learners are intrinsically motivated to learn in a situation in which they feel competent and self-determined. Evidence indicates that a supportive learning atmosphere has a major influence on student competency and attitudes toward learning (Pan, 2014).

Educational institutions can also play a crucial role to support students in this pandemic situation. The home confinement triggered by COVID-19 limits access to the faster networks readily available at educational institutions (Beaunoyer et al., 2020). When students are deprived of such facilities, educational institutions should subsidise the internet cost for students from low-income families. Educational institutions should further facilitate student learning by providing necessary information and basic technology devices to overcome the challenges of online learning (Huang, Liu, Tlili, Yang, \& Wang, 2020).

Based on the understanding of different constructs of students' readiness amidst a pandemic situation, we therefore propose a reconceptualised model of students' readiness for online learning. This model consists of three key components: motivation, self-efficacy, and situational factors. Further, in this model we conceptualise situational factors as a combination of three sub-constructs: digital access, learning atmosphere and institutional support.

Based on the understanding of different constructs of students' readiness amidst a pandemic situation, we therefore propose a reconceptualised model of students' readiness for online learning. This model consists of three key components: motivation, self-efficacy, and situational factors. Further, in this model we conceptualise situational factors as a combination of three sub-constructs: digital access, learning atmosphere and institutional support.

\section{Research Methods}

\subsection{Scale development}

The proposed model discussed in the previous section guided our scale development process, and this was finalised in four different phases suggested by DeVillis (2016). First, we generated items under the three major constructs presented in figure 1, based on related previous research. A five-point Likert scale was developed with a continuum from strongly agree to strongly disagree to measure the strength of students' attitude for each item in the survey. Second, we modified and refined the items based on experts' feedback. Third, we conducted a pilot study with a sample of 68 university students to check initial internal consistency and inter-item correlations for a further refinement of the survey items. Finally, we tested the reliability and validity of the survey scale using a larger student sample in the actual study using a more advanced statistical approach i.e., structural equation modelling (SEM). 
One of the key constructs in our proposed model is motivation. Motivation, as conceptualised in our study, delineates students' willingness to use online learning platforms during the COVID-19 pandemic. Guided by self-determination theory (Ryan \& Deci, 2000), we considered students' intrinsic motivation i.e. interest or enjoyment, and extrinsic motivation i.e. perceived usefulness and reinforcement, to be the key aspects to measure students' motivation in our study. Previous studies showed positive correlations between these motivational factors and students' level of online readiness and their rates of participation (Doe et al., 2017; Hung et al., 2010; M. K. O. Lee, Cheung, \& Chen, 2005; Xie, Debacker, \& Ferguson, 2006; Xiong et al., 2015). Therefore, we adapted seven items from Hung et al. (2010), Xiong et al. (2015) and "Intrinsic Motivation Inventory (IMI)") rooted in the theory of self-determination (Ryan \& Deci, 2000) to measure student interest; seven items from Intrinsic Motivation Inventory and Xiong et al. (2015) to measure perceived usefulness; four items (two from Xiong et al. (2015) and two newly created) to measure reinforcement.

Self-determination theory further contends that students' connectedness with their teachers and peers are a vital component of student motivation. Previous literature also demonstrates the importance of engaging in human-human interactions and the sense of being part of a learning community for effective learning in online settings (Joksimović, Gašević, Kovanović, Riecke, \& Hatala, 2015). Students get a feeling of connectedness to other students through online learning communities and this contributes to meaningful learning experiences (Cho \& Tobias, 2016). Therefore, we adapted eight items from Intrinsic Motivation Inventory to measure students' feeling of connectedness in online learning during the pandemic.

The second key construct in our model is self-efficacy which focuses on how competent students are to adopt and use the technology and to benefit from them. Studies show that self-efficacy is a major driving factor in preparing students for online learning (Arthur-Nyarko, Agyei, \& Armah, 2020a; Doe et al., 2017; Hung et al., 2010; Xiong et al., 2015) and that social and technical competency, two key dimensions of self-efficacy for student learning, are highly associated with online readiness and satisfaction (Yu, 2018; Yu \& Richardson, 2015). Thus, in order to measure students' technical and social competency, we adapted four and ten items from Yu and Richardson (2015) and Hung et al. (2010), respectively.

The final constructs in our study are characterized as situational factors which describe the contextual dynamics emerging from the COVID-19 pandemic. As discussed in section 2.2, we conceptualised this construct as the combination of three sub-constructs i.e., digital access, learning atmosphere and institutional support. The recent literature (discussed in section 2.2) shows that these factors are highly related to students' online learning during the pandemic. Thus, we have created twelve new items under the situational factors (four items for learning atmosphere, four items for institutional support and four items for digital access) to examine their relationships and influence on students' readiness for online learning. In total, there were 52 items in the initial survey instrument (see Appendix A).

\subsection{Research Contexts and Participants}

The researchers started distributing the online survey during the peak of COVID-19 at the beginning of June 2020, when all the higher educational institutes of Bangladesh were in a locked down state. Most of the educational institutions had started online teaching by this time. The survey was created using Google form and administered nationwide in a total of 23 universities. To achieve a representative sample for the study, participants were invited from all three types of universities: public (government funded), private, and international (funded by international donor agencies). Only engineering students were invited to participate and students who did not undertake any online classes during the COVID-19 pandemic were excluded from the survey. This ensured that participating students had a minimum experience in online classes, and they could properly reflect their state of readiness for online learning.

\subsection{Data Collection and Preparation}


The researchers asked respective course teachers in the 23 universities to distribute the survey among their students. The survey ran for a two-month period between mid-June to mid-August 2020 and initially a total of 1038 responses were collected.

After a rigorous data cleaning and screening process, 988 responses were found to be valid. The data set had been scrutinized for missing values, normality, outliers, skewness, and kurtosis coefficients. Initial analysis of the raw dataset of 1038 responses revealed that only one response had major missing data and nine responses had come from disciplines other than engineering. Therefore, these ten responses were removed from the dataset. Furthermore, 36 apparently unengaged students had been identified (for example patterns were evident in their responses such as all 52 item responses were either strongly agreed or strongly disagreed) and eliminated from the data set. Thereafter, four responses had been identified as outliers and eliminated which reduced the final dataset to 988 responses. Table 1 shows the summary of the participants' demographic data.

Table 1: Summary of the demographics of the participants

\begin{tabular}{|c|c|c|c|c|c|c|c|}
\hline Demographic & Category & $\begin{array}{l}\text { Frequency } \\
(n=988)\end{array}$ & Percent & Demographic & Category & $\begin{array}{l}\text { Frequency } \\
(n=988)\end{array}$ & Percent \\
\hline \multirow[t]{2}{*}{ Gender } & Male & 781 & 79.0 & \multirow[t]{5}{*}{ Discipline } & EEE & 370 & 37.4 \\
\hline & Female & 207 & 21.0 & & $\mathrm{ME}$ & 234 & 23.7 \\
\hline \multirow{3}{*}{$\begin{array}{l}\text { University } \\
\text { Type }\end{array}$} & Public & 196 & 19.8 & & CSE & 234 & 23.7 \\
\hline & Private & 415 & 42.0 & & $\mathrm{CE}$ & 99 & 10.0 \\
\hline & International & 377 & 38.2 & & TE & 51 & 5.2 \\
\hline \multirow[t]{5}{*}{$\begin{array}{l}\text { Place of } \\
\text { living }\end{array}$} & City & 581 & 58.8 & \multirow[t]{5}{*}{$\begin{array}{l}\text { Educational } \\
\text { Level }\end{array}$} & $\begin{array}{l}\text { Undergraduate } \\
\text { Year } 1\end{array}$ & 223 & 22.6 \\
\hline & $\begin{array}{l}\text { District } \\
\text { Town }\end{array}$ & 110 & 11.1 & & $\begin{array}{l}\text { Undergraduate } \\
\text { Year } 2\end{array}$ & 226 & 22.9 \\
\hline & Thana Town & 81 & 8.2 & & $\begin{array}{l}\text { Undergraduate } \\
\text { Year } 3\end{array}$ & 206 & 20.9 \\
\hline & Village & 216 & 21.9 & & $\begin{array}{l}\text { Undergraduate } \\
\text { Year } 4\end{array}$ & 302 & 30.6 \\
\hline & & & & & Postgraduate & 31 & 3.1 \\
\hline
\end{tabular}

[EEE: Electrical and Electrical Engineering and related disciplines; ME: Mechanical Engineering and related disciplines; CSE: Computer Science and Engineering and related disciplines; CE: Civil Engineering; TE: Textile Engineering]

Finally, the five negatively worded items (i.e., MI2, MC3, MC4, LA4, DA4) in the survey scale (see Appendix A) were reverse coded to ready the data set for further analysis. The reliability and descriptive statistics of the data set are shown below in Table 2.

Table 2 : Reliability and descriptive statistics of the theoretical constructs 


\begin{tabular}{|llllll|}
\hline Constructs & & Mean & Std. Deviation & Skewness & Kurtosis \\
\hline Motivation & Interest & 18.45 & 7.32 & .319 & -.757 \\
\cline { 2 - 6 } & Usefulness & 18.59 & 7.56 & .311 & -.856 \\
\cline { 2 - 6 } & Reinforcement & 11.58 & 4.18 & .076 & -.824 \\
\cline { 2 - 6 } & Connectedness & 21.67 & 6.94 & .176 & -.584 \\
Self-efficacy & Technology competency & 13.93 & 3.99 & -.403 & -.440 \\
$\mathrm{a}=0.926$ & Social competency & 29.68 & 9.21 & .101 & -.608 \\
\hline Situational Factors & Learning atmosphere & 12.81 & 4.06 & -.043 & -.769 \\
\cline { 2 - 6 }$a=0.868$ & Institutional support & 13.18 & 4.16 & -.265 & -.654 \\
\cline { 2 - 6 } & Digital access & 12.46 & 3.93 & .038 & -.610 \\
\cline { 2 - 6 } & & & & & \\
& & & &
\end{tabular}

Table 2 shows that the coefficient alpha values were well above 0.8 which showed very good internal consistency among the items. Internal consistency higher than 0.9 is regarded as excellent, and higher than 0.7 as acceptable (Blunch, 2008). Each measurement variable is evaluated to check for normality. When normality assumption is violated, an inaccurate estimate is attained, and correct statistical validation is difficult to achieve in structural equation modeling. Therefore, to test the multivariate normality assumption of the data set we assessed the mean, standard deviation, skewness, and kurtosis. A previous study showed that skewness $<3.0$ and kurtosis $<10$ met the assumptions of multivariate normality (Kline, 2016). Thus, our data set met assumptions of multivariate normality.

\subsection{Data Analysis}

This study used structural equation modelling (SEM) (Anderson \& Gerbing, 1988; Lei \& Wu, 2007) to validate the structural relationships among the variables of student online readiness. Once the structural model was validated, we ran a multivariate analysis of variance (MANOVA) to explore the students' readiness for online learning for different demographic variables.

We developed most of the constructs and their relevant items based on previous literature, however, as they were reconceptualised for the COVID-19 situation, it was important to explore and validate the underlying relationships between the latent constructs in this context. Therefore, we first conducted an exploratory factor analysis (EFA) to determine the relationships between latent variables reflected in the items of the survey instrument (Hair, Black, Babin, Anderson, \& Tatham, 2010). In doing so, we ran a parallel analysis (Monte Carlo simulation) using a statistical program (Watkins, 2000) to identify the exact number of factors to keep for EFA analysis. This method of determining the number of factors for EFA is found to be the most accurate since both Kaiser's (1960) criterion of using eigenvalues larger than one and Cattell's (1966) scree test have a tendency to overestimate the number of factors required (Hubbard \& Allen, 1987; Zwick \& Velicer, 1986). We also examined the sampling adequacy by testing the Kaiser-Meyer-Olkin (KMO) measure and Bartlett's test of sphericity to establish the construct validity of the EFA model. We also ensured that all items met the recommended threshold values of communality. Table 3 shows the recommended index values for EFA analysis used in this study.

Table 3: Recommended index values for EFA used in this study 


\begin{tabular}{|lll|}
\hline Indicators & Recommended value & Source \\
\hline Kaiser-Meyer-Olkin (KMO) & $>0.70$ & Hutcheson and Sofroniou (1999) \\
\hline Bartlett's test of sphericity & Significant at $\mathrm{p}<0.001$ & Field (2013) \\
\hline Satisfactory communalities values & $>0.50$ & Field (2013) \\
\hline Total variance explained & $>50 \%$ & Podsakoff and Organ (1986) \\
\hline The variance for the first factor & $<50 \%$ & Podsakoff and Organ (1986) \\
\hline Factor loading for items & $>0.50$ & (Hair, Hult, Ringle, \& Sarstedt, 2016) \\
\hline
\end{tabular}

When undertaking SEM, Anderson and Gerbing (1988) proposed that analysis of data be completed in two stages. First, to determine the construct validity of the measurement model, and second, to assess the structural model by examining the model fit and relationship strength among the factors.

In the measurement model, we examined the reliability, convergent validity, and discriminant validity of our proposed model to determine the construct validity. Composite Reliability (CR) was assessed to examine the factor reliability. Average Variance Extracted (AVE) was used to determine the convergent validity of the factors. To confirm the discriminant validity, we examined whether all square roots of AVEs were greater than the inter factor correlations and all AVEs were greater than the MSVs (Maximum Shared Variance).

In the structural model, we assessed the model fit against several tests and fit indices recommended by literature. The popular technique of testing the model fit is to use the chi-square test. Typically, a non-significant chi-square value implies a good model fit. However, researchers suggest that the chi-square test is sensitive to sample size and usually rejects the admissibility of the model for a sample size greater than 200 (Bentler \& Bonett, 1980; Byrne, 1998; Levesque, Zuehlke, Stanek, \& Ryan, 2004). Likewise, Hair et al. (2010) said that complex models and models with large sample sizes typically offer significant chi-square values. Considering these reports, we used several other recommended fit indices, namely the normed fit index (NFI), the comparative fit index (CFI), Tucker Lewis Index (TLI), Incremental Fit Index (IFI), Standardized Root Mean Square Residual (SRMR), and the Root Mean Square Error of Approximation (RMSEA), to evaluate the model fit of our proposed model (see Table 8 for details).

\section{Results}

\subsection{Exploratory Factor Analysis}

We used parallel analysis to identify the exact number of components to best reflect the underlying relationship among the variables. Parallel analysis compares the eigenvalues obtained from principal component analysis (PCA) during EFA with the randomly generated data in a Monte Carlo software program. We kept only those components with the eigenvalues greater than the randomly generated data from parallel analysis (see Table 4).

Table 4: Outcome from parallel analysis 


\begin{tabular}{|llll|}
\hline Components & Eigenvalue from PCA & Random value from parallel analysis & Decision \\
\hline $\mathbf{1}$ & 22.3751 & 1.4685 & Accept \\
$\mathbf{2}$ & 3.5368 & 1.4246 & Accept \\
\hline $\mathbf{4}$ & 2.2804 & 1.3929 & Accept \\
\hline $\mathbf{6}$ & 1.6592 & 1.3650 & Accept \\
$\mathbf{6}$ & 1.3130 & 1.3400 & Reject \\
\hline
\end{tabular}

We selected principal component analysis (PCA) as the extraction method and Promax rotation with Kaiser normalization to run the four accepted factors EFA. For a cleaner solution as regards to rotated results matching to Thurstone's (1931) idealized simple structure result, items with low communalities (less than 0.5) were eliminated. Also, we retained only items with greater than 0.5 factor loadings under each construct. Additionally, the higher cross loading items in more than two factors were scrutinised and eliminated to further simplify the model. In this process, a total of 13 items were deleted from the original 52 items and the remaining 39 items were retained for the EFA model. Exploratory factor analysis suggested a one-factor model for the variables of interest, usefulness, reinforcement, and relatedness which when combined denote as motivation. Similarly, items of technology skills and social competency greater than 0.5 factor loadings being loaded under self-efficacy construct. We also observed a few items from selfefficacy loaded under motivation, and one item from self-efficacy under the learning atmosphere. We retained these items for further analysis in CFA. Interestingly, situational factors indicated a two-factor model and we denoted them as learning atmosphere and institutional support.

Table 5 shows excellent internal consistency (Cronbach's alpha) of the items in the four factors EFA model with the lowest alpha coefficient being 0.853 . High loading variables are grouped together to meet the convergent validity requirement, and discriminant validity is also ensured as no cross loading of the items are observed in more than one factor. Further, inter factor correlations are below 0.70 which also confirms discriminant validity. For the measure of sampling adequacy, Bartlett's tests of sphericity were found to be significant $(0.000 ; P<.001)$, suggesting the suitability of factor analyses. Also, KMO (Kaiser-Meyer-Olkin) shows an excellent value (.980) which meets the criteria of data adequacy for factor analyses (Kaiser \& Rice, 1974).

Table 5: *Inter factor correlation matrix, reliability, and sampling adequacy of the EFA model 


\begin{tabular}{|llllll|}
\hline Factors & $\mathbf{1}$ & $\mathbf{2}$ & $\mathbf{3}$ & $\mathbf{4}$ & Reliability (a) \\
\hline 1. Motivation & 1.000 & & & 0.971 \\
\hline 2. Self-efficacy & .461 & 1.000 & & 0.863 \\
\hline 3. Learning atmosphere & .633 & .488 & 1.000 & & 0.860 \\
\hline 4. Institutional support & .580 & .333 & .581 & 1.000 & 0.853 \\
\hline Sampling Adequacy & & & & \\
KMO & 0.980 & & & \\
\hline Bartlett's tests of sphericity & $0.000 * \star \star$ & & & \\
\hline Total Variance Explained & $62.62 \%$ & & \\
\hline *Extraction Method: Principal Component Analysis; Rotation Method: Promax with Kaiser Normalization \\
***Significant at P<.001
\end{tabular}

\subsection{Measurement Model}

We ran confirmatory factor analysis (CFA) with AMOS (version 24) to examine the composite reliability, convergent and discriminant validity of the EFA model. However, in validating the measurement model, we found some problematic items and therefore, following established data-analysis practices (MacCallum, Browne, \& Sugawara, 1996), nine items needed to be deleted which eventually reduced the model to 30 items. In deleting these items, we checked content validity ensuring adequate items, i.e., at least four items remain loaded under each measurement construct.

In Table 6, the composite reliability (CR) for each construct of the final model was found to be greater than 0.7 which ensures the reliability of the factors. CFA shows adequately high factor loadings on the corresponding components which support convergent validity. According to Hair et al. (2010), standardized regression weights in the measurement model should be greater than 0.5 . The standardized regression weights were found to be between 0.64 and 0.85 at $p<$ .001 in the measurement model. We also assessed the average variance extracted (AVE) for each construct and found that all the values are larger than 0.50 which indicates the criteria of convergent validity has been fulfilled (Fornell \& Larcker, 1981).

Table 6: Convergent and discriminant validity of the measurement model

\begin{tabular}{|llllllll|}
\hline Constructs & CR & AVE & MSV & $\mathbf{1}$ & $\mathbf{2}$ & $\mathbf{3}$ & $\mathbf{4}$ \\
\hline 1. Motivation & 0.967 & 0.623 & 0.442 & $\mathbf{0 . 7 9 0}$ & & & \\
\hline 2. Self-efficacy & 0.824 & 0.540 & 0.528 & $0.665^{\star \star \star}$ & $\mathbf{0 . 7 3 5}$ & & \\
\hline 3. Learning atmosphere & 0.831 & 0.555 & 0.528 & $0.659^{\star \star \star}$ & $0.727^{\star \star *}$ & $\mathbf{0 . 7 4 5}$ & \\
\hline 4. Institutional Support & 0.856 & 0.600 & 0.425 & $0.652^{\star \star *}$ & $0.607 * \star \star$ & $0.533^{\star \star *}$ & $\mathbf{0 . 7 7 5}$ \\
\hline
\end{tabular}

*** significant at $p<.001$

We also assessed discriminant validity, as shown in Table 6, and found that our model met the criteria of discriminant validity as all square root of AVEs (Average Variance Extracted) are greater than the inter factor correlations and all AVEs are greater than the MSVs (maximum shared variance) (Fornell \& Larcker, 1981). The correlations of the constructs and 
the square root of the AVE on the diagonal (in bold numbers) are shown in Table 6. Further, we used heterotraitmonotrait (HTMT) ratio of correlations to assess the discriminant validity as shown in Table 7. All values of the constructs are below .850 and this shows a strict discriminant validity between the factors (Fornell \& Larcker, 1981; Henseler, Ringle, \& Sarstedt, 2015).

Table 7: HTMT Analysis

\begin{tabular}{|lllll|}
\hline Constructs & $\mathbf{1}$ & $\mathbf{2}$ & $\mathbf{3}$ & $\mathbf{4}$ \\
\hline 1. Motivation & - & & & \\
\hline 2. Self-efficacy & 0.687 & - & & \\
\hline 3. Learning atmosphere & 0.671 & 0.757 & - & \\
\hline 4. Institutional support & 0.668 & 0.628 & 0.562 & - \\
\hline
\end{tabular}

In sum, the evaluation of the measurement model suggested that all items are reliable and met the conditions of convergent and discriminant validity.

\subsection{Structural model}

The structural model was tested to assess how latent constructs are related to one another in the theoretical model.

First, goodness-of-fit of the model was evaluated in SEM. Table 8 presents the recommended values of the fit indices and the corresponding results of the proposed model. Hu and Bentler (1999) state that a RMSEA value less than 0.07, and CFI and TLI values greater than 0.90 indicate good fit of a model. In our study, the value of the RMSEA coefficient is 0.063 , and other indicators (CFI, TLI, IFI, and NFI) are all above 0.90 which indicate a good fit for the model. SRMR fit index is also smaller than 0.10 , further confirming.

Table 8: Recommended values of the fit indices and the corresponding results of the proposed model

\begin{tabular}{|lllll|}
\hline Fit Index & Admissibility & Source & Result & $\begin{array}{c}\text { Fit (Yes/ } \\
\text { No) }\end{array}$ \\
\hline CMIN/DF & $<5.0$ & Hu and Bentler (1999); Kline (2016) & $(1954.32 / 399)$ & Yes \\
& & & 4.898 & \\
\hline RMSEA & $<0.08$ & $\begin{array}{l}\text { Byrne (1998); MacCallum et al. (1996); Hu and Bentler } \\
(1999)\end{array}$ & 0.063 & Yes \\
\hline CFI & $>0.90$ & Bentler (1992); Hu and Bentler (1999) & Yes \\
\hline TLI & $>0.90$ & Bentler (1992); Hu and Bentler (1999); & 0.929 & Yes \\
\hline IFI & $>0.90$ & Bentler (1992); Hu and Bentler (1999); & 0.923 & Yes \\
\hline NFI & $>0.80$ & $\begin{array}{l}\text { Bentler and Bonett (1980); Schumacker and Lomax } \\
(2010)\end{array}$ & 0.929 & Yes \\
\hline SRMR & $<0.10$ & Hu and Bentler (1999) & 0.912 & Yes \\
\hline
\end{tabular}


Thus, we conclude that our model met all the recommended levels of fit indices. We also checked for multicollinearity to identify whether there is any theoretically and/or empirically redundant variable included in the model. We assessed this using variance inflation factor (VIF) and found that all the values are between 1.903 and 3.550. Traditionally, VIF values above 5 are regarded as indications of problematic multicollinearity (Hair et al., 2016) and above 10 implies a severe multicollinearity issue (Kline, 2016). Thus, the VIF values met the criteria to support the structural model.

Second, we examined the path coefficients which signify the strengths of the relationships between the factors. Table 9 shows the path coefficients and path significances revealing that all values are significant (at $p=.001$ ). Figure 2 illustrates $R^{2}$ values representing the amount of variance explained by the constructs. Student motivation is found to be significantly determined $\left(R^{2}=0.58\right)$ by the learning atmosphere, institutional support, and through the effect of selfefficacy. This implies $58 \%$ variance in motivation is explained by these three factors. Likewise, self-efficacy is found to be significantly determined $\left(R^{2}=0.60\right)$ by the learning atmosphere and institutional support. Thus, learning atmosphere and institutional support have explained $60.0 \%$ of variance in self-efficacy.

Table 9: Model path analysis

\begin{tabular}{|llllllll|}
\hline Path relationships & & Unstandardized Estimate & S.E. & P & $\begin{array}{l}\text { Standardized estimate } \\
\text { (beta coefficient) }\end{array}$ \\
\hline Self-efficacy & $<-$ & Learning atmosphere & .654 & & .050 & $\star * *$ & .563 \\
\hline Self-efficacy & $<-$ & Institutional support & .287 & .034 & $\star * *$ & .307 \\
\hline Motivation & $<-$ & Institutional support & .373 & .037 & $\star * *$ & .349 \\
\hline Motivation & $<-$ & Self-efficacy & .263 & .053 & $\star * *$ & .230 \\
\hline Motivation & $<-$ & Learning atmosphere & .406 & .058 & $\star * *$ & .306 \\
\hline
\end{tabular}

*** significant at $p<.001$

Finally, in Table 10, bootstrapping is used to determine whether there is any mediation effect. When bootstrapping was run to identify the specific indirect effects for every mediation possible, we found that both the relationships between learning atmosphere and motivation, and institutional support and motivation are significantly mediated by self-efficacy at $p=0.001$.

Table 10: Mediation effect in the structural model

\begin{tabular}{|c|c|c|c|c|c|}
\hline Relationships & $\begin{array}{l}\text { Unstandardized } \\
\text { Estimate }\end{array}$ & Lower & Upper & $\mathbf{P}$ & $\begin{array}{l}\text { Standardized } \\
\text { Estimate }\end{array}$ \\
\hline $\begin{array}{l}\text { Institutional support -> self-efficacy } \rightarrow> \\
\text { motivation }\end{array}$ & .075 & .048 & .115 & .001 & $.071 \star \star \star$ \\
\hline $\begin{array}{l}\text { Learning atmosphere -> self-efficacy -> } \\
\text { motivation }\end{array}$ & .172 & .112 & .247 & .001 & 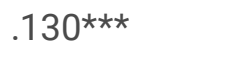 \\
\hline
\end{tabular}

*** significant at $p<.001$

\subsection{Student readiness for online learning}


As discussed in the literature, student's preparedness for online learning can be influenced by digital access, therefore the availability and speed of internet connection become important indicators of students' readiness. We asked a question about the type of internet connection students are using during the COVID-19 pandemic. It was found that a significant portion (35.73\%) of the students depend on mobile data (see Figure 3 ) which is more expensive than other connection types, and provides slower speed compared to the other internet connections in Bangladesh.

When asked about their preferred method for online class engagement, $22.98 \%$ of the students were in favour of prerecorded lectures. Interestingly, $8.10 \%$ of the students do not like to participate in any form of online classes. This clearly indicates that a significant portion (22.98\% and $8.18 \%)$ of the students are uncomfortable engaging in live online class.

We conducted multivariate analysis of variance (MANOVA) to examine the effect of gender, type of university, place of living, and academic study level on students' readiness for online learning (i.e., motivation and self-efficacy). We tested all the assumptions for MANOVA to verify the sample distribution, linearity, normality, multicollinearity, univariate and multivariate outliers, and homogeneity of variance-covariance. We noticed no significant violation of any assumptions. Table 11 shows the MANOVA results on the impact of demographic variables.

Table11: MANOVA analysis showing the impact of demographic variables on students' readiness

\begin{tabular}{|lllllll|}
\hline Demographic variables & Wilk's lambda $(\boldsymbol{\lambda})$ & $\mathbf{F}$ & Hypothesis df & Error df & $\mathbf{P}$ & Partial eta squared \\
\hline Gender & .987 & 6.560 & 2.0 & 985.0 & $.001 *$ & .013 \\
\hline University & .910 & 23.873 & 4.0 & 1968.0 & $.000 *$ & .046 \\
\hline Study Level & .983 & 2.130 & 8.0 & 1964.0 & $.030 *$ & .009 \\
\hline Place of living & .951 & 8.338 & 6.0 & 1966.0 & $.000 *$ & .025 \\
\hline
\end{tabular}

*significant at $p<.05$

The results of the MANOVA analysis suggest a statistically significant effect of all demographic variables on student readiness for online learning. We ran a separate analysis of variance (ANOVA) test to examine the statistical significance of the demographic variables for each of the results of the dependent variables (i.e., motivation and selfefficacy). When we found the ANOVA result to be significant between three or more group means, we further conducted a multiple-comparison analysis (post hoc) with Tukey's test to show exactly where the differences existed (see Table 12 for details).

Table 12: F test results for demographic variables on students' readiness for online learning 


\begin{tabular}{|c|c|c|c|c|c|c|c|c|c|c|}
\hline $\begin{array}{l}\text { Demographic } \\
\text { variables }\end{array}$ & $\begin{array}{l}\text { Student } \\
\text { readiness }\end{array}$ & Category & $M$ & SD & $d f$ & Error & $\mathbf{F}$ & $\mathbf{P}$ & $\begin{array}{l}\text { Partial } \\
\text { eta } \\
\text { squared }\end{array}$ & $\begin{array}{l}\text { Post } \\
\text { hoc }\end{array}$ \\
\hline \multirow[t]{4}{*}{ Gender } & \multirow[t]{2}{*}{ Motivation } & 1. Male & 48.66 & 19.14 & \multirow[t]{2}{*}{1} & \multirow[t]{2}{*}{986} & \multirow[t]{2}{*}{12.96} & \multirow[t]{2}{*}{$.000 *$} & \multirow[t]{2}{*}{.013} & \multirow[t]{2}{*}{-} \\
\hline & & 2. Female & 43.38 & 17.24 & & & & & & \\
\hline & \multirow{2}{*}{$\begin{array}{l}\text { Self- } \\
\text { efficacy }\end{array}$} & 1. Male & 13.69 & 3.84 & \multirow[t]{2}{*}{1} & \multirow[t]{2}{*}{986} & \multirow[t]{2}{*}{6.35} & \multirow[t]{2}{*}{$.012^{\star}$} & \multirow[t]{2}{*}{.006} & \multirow[t]{2}{*}{-} \\
\hline & & 2. Female & 12.94 & 3.80 & & & & & & \\
\hline \multirow[t]{6}{*}{ University } & \multirow[t]{3}{*}{ Motivation } & 1. Public & 52.37 & 19.80 & \multirow[t]{3}{*}{2} & \multirow[t]{3}{*}{985} & \multirow[t]{3}{*}{45.965} & \multirow[t]{3}{*}{$.000 *$} & \multirow[t]{3}{*}{.085} & \multirow{3}{*}{$\begin{array}{l}1>3 \\
2>3\end{array}$} \\
\hline & & 2. Private & 51.65 & 18.38 & & & & & & \\
\hline & & $\begin{array}{l}3 . \\
\text { International }\end{array}$ & 40.55 & 16.74 & & & & & & \\
\hline & \multirow{3}{*}{$\begin{array}{l}\text { Self- } \\
\text { efficacy }\end{array}$} & 1. Public & 14.09 & 3.73 & \multirow[t]{3}{*}{2} & \multirow[t]{3}{*}{985} & \multirow[t]{3}{*}{8.065} & \multirow[t]{3}{*}{$.000 *$} & \multirow[t]{3}{*}{.016} & \multirow{3}{*}{$\begin{array}{l}1>3 \\
2>3\end{array}$} \\
\hline & & 2. Private & 13.82 & 3.83 & & & & & & \\
\hline & & $\begin{array}{l}3 . \\
\text { International }\end{array}$ & 12.93 & 3.83 & & & & & & \\
\hline \multirow[t]{10}{*}{ Study Level } & \multirow[t]{5}{*}{ Motivation } & $\begin{array}{l}1 . \\
\text { Undergraduate } \\
\text { Year } 1\end{array}$ & 45.54 & 18.78 & 4 & 983 & 3.750 & $.005^{\star}$ & .015 & $\begin{array}{l}5> \\
1,2\end{array}$ \\
\hline & & $\begin{array}{l}2 . \\
\text { Undergraduate } \\
\text { Year } 2\end{array}$ & 45.50 & 18.92 & & & & & & \\
\hline & & $\begin{array}{l}3 . \\
\text { Undergraduate } \\
\text { Year } 3\end{array}$ & 48.36 & 19.02 & & & & & & \\
\hline & & $\begin{array}{l}4 . \\
\text { Undergraduate } \\
\text { Year } 4\end{array}$ & 49.09 & 18.56 & & & & & & \\
\hline & & $\begin{array}{l}5 . \\
\text { Postgraduate }\end{array}$ & 56.68 & 17.99 & & & & & & \\
\hline & $\begin{array}{l}\text { Self- } \\
\text { efficacy }\end{array}$ & $\begin{array}{l}1 . \\
\text { Undergraduate } \\
\text { Year } 1\end{array}$ & 13.22 & 3.83 & 4 & 983 & 2.611 & $.034^{\star}$ & .011 & $5>1$ \\
\hline & & $\begin{array}{l}2 . \\
\text { Undergraduate } \\
\text { Year } 2\end{array}$ & 13.27 & 4.03 & & & & & & \\
\hline & & $\begin{array}{l}3 . \\
\text { Undergraduate } \\
\text { Year } 3\end{array}$ & 13.47 & 3.95 & & & & & & \\
\hline & & $\begin{array}{l}4 . \\
\text { Undergraduate } \\
\text { Year } 4\end{array}$ & 13.83 & 3.57 & & & & & & \\
\hline & & $\begin{array}{l}5 . \\
\text { Postgraduate }\end{array}$ & 15.22 & 3.78 & & & & & & \\
\hline $\begin{array}{l}\text { Place of } \\
\text { living }\end{array}$ & Motivation & 1. City & 45.64 & 18.57 & 3 & 984 & 7.255 & $.000 *$ & .022 & $\begin{array}{l}4>1, \\
2\end{array}$ \\
\hline & & 2. District & 46.28 & 18.09 & & & & & & \\
\hline
\end{tabular}




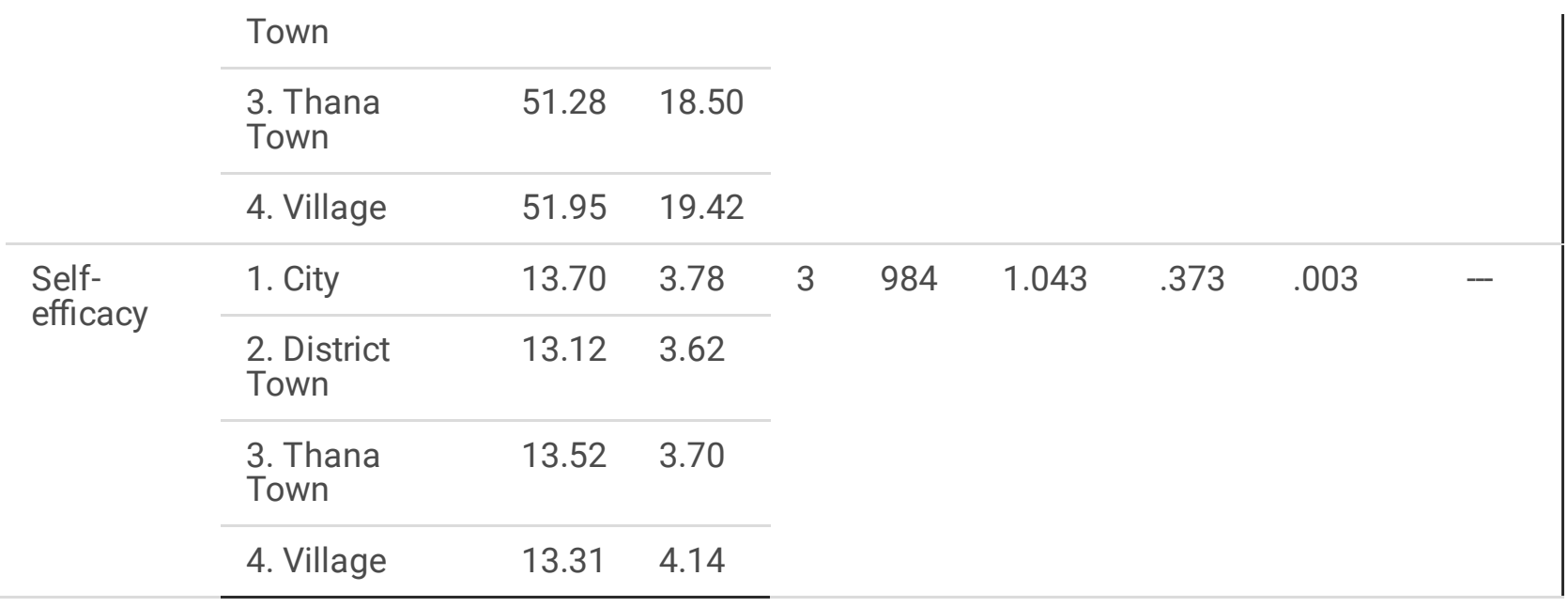

*significant at $p<.05$

The results indicate statistically significant impact on student readiness as follows:

- Gender showed a statistically significant impact on students' readiness for online learning, $F(1,986)=12.96, p=$ .000 , partial eta squared $=.013$, with male $(M=48.66)$ scoring higher than female $(M=43.38)$ in motivation; and $F$ $(1,986)=6.35, p=.012$, partial eta squared $=.006$, with male $(M=13.69)$ scoring higher than female $(M=12.94)$ in self-efficacy.

- University type revealed a statistically significant influence on students' readiness in motivation, $F(2,985)=45.965$, $p=.000$, partial eta squared $=.085$, with public university $(M=52.37)$ scoring higher than international university ( $M$ $=40.55)$, and private university $(M=51.65)$ also scoring higher than international university $(M=40.55)$.

- Likewise, $F(2,985)=8.065, p=.000$, partial eta squared $=.016$, with public university $(M=14.09)$ scoring higher than international university $(M=12.93)$, and private university $(M=13.82)$ again scoring higher than international university $(M=12.93)$ in self-efficacy.

- Study level showed a statistically significant impact on students' readiness for online learning, $F(4,983)=3.750, p$ $=.005$, partial eta squared $=.015$, with postgraduate students $(M=56.68)$ scoring higher than year $1(M=45.54)$ and year $2(M=45.50)$ students in motivation; and $F(4,983)=2.611, p=.034$, partial eta squared $=.011$, with postgraduate students $(M=15.22)$ scoring higher than year $1(M=13.22)$ students in self-efficacy.

- Living place showed a statistically significant impact on students' readiness, $F(3,984)=7.255, p=.000$, partial eta squared $=.022$, with village students $(M=51.95)$ scoring higher than both city $(M=45.64)$ and district town $(M=$ 46.38) students in motivation.

- No statistically significant differences were found for living places in self-efficacy.

\section{Discussion}

This study surveyed engineering students' readiness for online learning during the COVID-19 pandemic in Bangladesh. To measure student readiness for online learning, we considered the well-known constructs: a) motivation and b) selfefficacy. Our reconceptualised model also theorized some situational factors to investigate whether/how these factors influence motivation and self-efficacy. Data suggests that motivation is influenced in three ways: directly by situational factors, and self-efficacy, while self-efficacy mediates the relationship between situational factors and motivation as well (see Tables 9 and10).

In this study, we have developed and proposed a model for measuring engineering students' readiness for online learning in the COVID-19 situation. In developing this context-specific model, we have combined three constructs: 
motivation, self-efficacy, and situational factors. Considering the unique situation of the COVID-19 pandemic, we have proposed the context-specific construct 'situational factors' which constitute information on i) availability of and access to digital resources, ii) learning atmosphere, and iii) the role of educational institutes. We have assessed the reliability, validity, and model fit evidence of the proposed survey scale. The model fit was found to be satisfactory for the specific context of COVID19 and similar emergency situations. The reliability and descriptive statistics of the data set proved to have very good internal consistency and the assumptions of multivariate normality were met. The model fit in the structural model was assessed against several tests and fit indices. The developed model was validated and found to be reliable for use in similar scenarios.

Exploratory Factor Analysis (EFA) suggests that all four sub-constructs, i.e., interest, usefulness, reinforcement, and connectedness, merge to form a single construct - motivation. This may be due to the pressing situation caused by COVID-19 in which all the four sub-constructs strongly correlate to each other and converge in one factor. Thus, we infer from our data that the COVID-19 situation exposes a need to reconceptualize motivation as a dominating component to determine students' online readiness. This finding is supported by the study of Naji et al. (2020) in which motivation was identified as one of the important factors for engineering students' online readiness. EFA also suggests that the three theorized situational factors can be merged into two constructs: learning atmosphere and institutional support.

The situational factors significantly determine student online readiness as the coefficient of determination, $\mathrm{R}^{2}$, indicates a high percentage of variance to explain motivation and self-efficacy (see Figure 2). Thus, situational factors play a significant role in determining student readiness during pandemic situations.

In this article we argue that learning atmosphere has a pronounced impact on the extent to which engineering students are ready for online classes. As a component of the learning atmosphere, the pedagogical mode plays a significant role in student readiness. For example, engineering students reported more enthusiasm in project-based courses than in nonproject-based courses ( $N a j i$ et al., 2020). Also, engineering students seem to be more engaged in a learning environment that offers practical-oriented, interactive, and team-based activities in an online learning environment (Kebritchi, Lipschuetz, \& Santiague, 2017; Radianti, Majchrzak, Fromm, \& Wohlgenannt, 2020). Boosting students' intrinsic motivation (Ryan \& Deci, 2000) by offering appropriate pedagogical modes and learning activities is likely to improve students' readiness for online classes (Hasan, Linger, Chen, Lu, \& Wang, 2016).

We also argue that institutional support plays a vital role in student motivation towards online learning and therefore their readiness learning online. If institutions provide timely IT support and a synchronized and reliable communication platform, students are likely to engage in online classes. Even if institutions provide support for online theory classes, however, more practical aspects of learning need to be included for effective online learning, especially for engineering students whose study involves practical concepts (Naji et al., 2020).

When a direct question was asked about the students' preferred online mode of participation, we found that approximately $30 \%$ of students did not like to engage in live online classes (see Figure $3 \mathrm{~b}$ ). This finding provides strong evidence of a low level of students' readiness for online learning during the emergency. Interestingly, students' unwillingness to engage in live online classes is commonly reported in the literature; for instance, in Handel's study (Händel et al., 2020) , only 6\% of students used live streaming. Further research may explore the emerging causes of students not willing to attend live classes.

Our data also suggest a digital inequality as a significant portion of students do not have adequate digital access in terms of internet connectivity (see Figure 3a). Using the Technology Acceptance Model (TAM) (Davis, 1989), as an investigation framework, Siron, Wibowo, and Narmaditya (2020) argued that individuals with prior experience using computers and the Internet demonstrated higher scores in 'perceived ease of use' of technology compared to new

Page $17 / 28$ 
learners, and this claim is supported by the works of Y.-H. Lee, Hsiao, and Purnomo (2014) and Purnomo and Lee (2013). Because these 'at risk' or digitally-not-ready students tend to be vulnerable, a careful and deliberate instructional strategy for their online learning is required.

Our findings revealed that the differences in students' demographics (gender, university type, study level, living place) have a significant impact on student online readiness. For example, male students are likely to be more motivated and efficient than female students. This finding is supported by the study of (Händel et al., 2020), however it contradicts the findings of Naji et al. (2020) and Chung et al. (2020) who reported no significant relationship between gender and student readiness. Further studies may result in better understanding of engineering students' readiness for online learning based on their gender.

Also, while differences were found among students of public, private, and international universities, the difference between public and private was not significant with respect to both motivation and self-efficacy. This may be due to some universal characteristic of students irrespective of their type of institution.

Results also revealed that the junior cohort student (year 1 and year 2) is less likely to be ready than students in the senior cohort (year 3, year 4 and postgraduate). In both motivation and self-efficacy no significant differences were found among senior students. Young university students have been found to be motivated toward learning and to perform better than the senior students (Abdullah, 2011). In our case, it may be due to the pandemic that senior students become more serious about their learning in order to complete their study and gain employment quickly.

An interesting finding was observed when students' readiness was explored with respect to their place of living. Our data showed that village students were more motivated in online classes than city students, whereas urban students enjoyed better access to the internet than village students. The village students may believe that having less access to technology could impact negatively on their academic performance. As such, they became more motivated but also anxious about gaining access to technology and joining online classes.

\section{Limitation, Implications, And Generalisation}

The survey used in this study employed convenience sampling for collecting data from the participants i.e., engineering students in Bangladesh. The convenience sampling method helps researchers to accumulate a sufficient number of participants needed for a certain research project, however this method can lead to unexpected or uncontrolled factors in the sample data which could potentially impact on the investigation and skew the results of the study (Emerson, 2015). This sampling method recruits participants who are easily accessible and this leads to the possibility of qualified individuals being missed in the survey (Etikan, Musa, \& Alkassim, 2016). However, a large sample group such as the current study may minimize the limitations posed by the convenience sampling. Also, as the name indicates, convenience sampling is often used despite its limitations due to the expediency of recruiting participants (Sedgwick, 2013). This sampling technique is also frequently utilized for quantitative studies whereas purposive sampling is more observed in qualitative studies (Etikan et al., 2016).

The insights derived from this study can be applied to similar situations - pandemic or otherwise - where students are required to shift to online learning due to some unwanted circumstances. Moreover, the findings will be applicable to other developing countries with similar sociodemographic conditions. Although this study focused on engineering students, some of the general findings can be applied to online learning for students from other disciplines as well.

This study presented some stimulating observations which could be considered vital for ensuring a proper learning environment for students. Support from educational institutes for students, in monetary or other form, would help foster a caring environment for learning. Lessons from the study could also help teaching staff improve and customize their 
course teaching for such situations to improve the learning experience for students. Furthermore, policy makers in developing countries should consider important evidence when preparing policies for teaching in similar conditions. Informed by the insights presented, academic entities may consider establishing counselling units dedicated to supporting the students' psychological wellbeing during the pandemic as this should enhance student confidence in online learning. This in turn will increase student satisfaction with the education offered by their respective institutions.

\section{Conclusion}

The focus of this study was to investigate engineering students' readiness for online learning during the COVID-19 situation. For this, we conducted an online survey in different universities in Bangladesh and after scrutiny, selected 988 responses out of 1038 initial responses. Our study proposed a new model to measure student readiness for online learning considering the context of the COVID-19 situation. Our study suggests that besides motivation and self-efficacy, situation and context-specific factors influence students' readiness for online learning. This study also shows that student readiness towards online learning can be hindered by digital inequality in a developing country. The proposed model can be utilized to improve the student learning experience in emergency situations as well as to address potential issues related to student online readiness. Further development of this study is to detect any changes in the relationship of factors through a longitudinal study. We also plan to extend this study by broadening the demographic distribution to include participants from different disciplines and locations. In our future study we wish to explore the relationship between teachers' readiness towards online teaching and their student's readiness for online learning.

\section{Declarations}

\section{A statement of ethics approval:}

The study is approved by the office of Research, Extension, Advisory Services and Publications (REASP) at Islamic University of Technology.

\section{A statement on participant consent:}

The participants were informed about the objectives of the research and they have given their consent to be a part of the study at the beginning of the online survey. No personal details were collected for this study that compromise anonymity of the participants.

3. A statement regarding potential competing interests:

The authors declare no competing interests.

\section{References}

Abdullah, A.-M. (2011). Factors affecting business students' performance in Arab Open University: The case of Kuwait. International Journal of Business and Management, 6(5), 146.

Ahmed, M. (2020a). Education Response to Covid-19 in Bangladesh-A Missing Opportunity? BANGLADESH EDUCATION JOURNAL, 18(1), 7-22.

Ahmed, M. (2020b). Managing schools, learning and student wellbeing during Covid-19. The Daily Star. Retrieved from https://www.thedailystar.net/opinion/news/managing-schools-learning-and-student-wellbeing-during-covid-19-1893556 
Allam, S. N. S., Hassan, M. S., Sultan, R., Mohideen, A. F. R., \& Kamal, R. M. (2020). Online Distance Learning Readiness During Covid-19 Outbreak Among Undergraduate Students. Journal of Academic Research in Business and Social Sciences, 10(5), 642-657.

Anderson, J. C., \& Gerbing, D. W. (1988). Structural equation modeling in practice: A review and recommended two-step approach. Psychological bulletin, 103(3), 411-423. doi:doi:10.1037/0033-2909.103.3.411

Arthur-Nyarko, E., Agyei, D. D., \& Armah, J. K. (2020a). Digitizing distance learning materials: Measuring students' readiness and intended challenges. Education and Information Technologies, 25, 2987-3002.

Arthur-Nyarko, E., Agyei, D. D., \& Armah, J. K. (2020b). Digitizing distance learning materials: Measuring students' readiness and intended challenges. Education and Information Technologies, 1-16.

Beaunoyer, E., Dupéré, S., \& Guitton, M. J. (2020). COVID-19 and digital inequalities: Reciprocal impacts and mitigation strategies. Computers in Human Behavior, 111, 106424. doi:https://doi.org/10.1016/j.chb.2020.106424

Bentler, P. M. (1992). On the fit of models to covariances and methodology to the Bulletin. Psychological bulletin, 112(3), 400-404.

Bentler, P. M., \& Bonett, D. G. (1980). Significance tests and goodness of fit in the analysis of covariance structures. Psychological bulletin, 88(3), 588.

Blunch, N. (2008). Introduction to structural equation modeling using IBM SPSS statistics and AMOS. Thousand Oaks, CA: Sage.

Byrne, B. M. (1998). Structural equation modeling with LISREL, PRELIS, and SIMPLIS: Basic concepts, applications, and programming. New Jersey: Lawrence Erlbaum Associates Inc.

Cattell, R. B. (1966). The scree test for the number of factors. Multivariate behavioral research, 1(2), 245-276. doi:DOI: $10.1207 / \mathrm{s} 15327906 \mathrm{mbr0102 \_ 10}$

Cho, M.-H., \& Tobias, S. (2016). Should instructors require discussion in online courses? Effects of online discussion on community of inquiry, learner time, satisfaction, and achievement. International Review of Research in Open and Distributed Learning, 17(2), 123-140.

Chowdhury, H., \& Alam, F. (2012). Engineering education in Bangladesh-an indicator of economic development. European Journal of Engineering Education, 37(2), 217-228.

Chung, E., Subramaniam, G., \& Dass, L. C. (2020). Online Learning Readiness Among University Students in Malaysia Amidst Covid-19. Asian Journal of University Education, 16(2), 45-58.

Cox, A. M. (2017). The experience of learning atmosphere in the learning commons. In iConference 2017 Proceedings (pp. 333-339): iSchools.

Davis, F. D. (1989). Perceived usefulness, perceived ease of use, and user acceptance of information technology. MIS quarterly, 319-340.

DeVillis, R. F. (2016). Scale development: Theory and applications (4th ed.). Chapel Hill: Sage.

Doe, R., Castillo, M. S., \& Musyoka, M. M. (2017). Assessing Online Readiness of Students. Online Journal of Distance Learning Administration, 20(1), 1-13.

Page 20/28 
Emerson, R. W. (2015). Convenience sampling, random sampling, and snowball sampling: How does sampling affect the validity of research? Journal of Visual Impairment \& Blindness, 109(2), 164-168.

Etikan, I., Musa, S. A., \& Alkassim, R. S. (2016). Comparison of convenience sampling and purposive sampling. American journal of theoretical and applied statistics, 5(1), 1-4.

Fernandes, N. (2020). Economic effects of coronavirus outbreak (COVID-19) on the world economy. Available at SSRN, 3557504. doi:http://dx.doi.org/10.2139/ssrn.3557504

Field, A. (2013). Discovering statistics using IBM SPSS statistics. Thousand Oaks, CA: sage.

Fornell, C., \& Larcker, D. F. (1981). Evaluating structural equation models with unobservable variables and measurement error. Journal of marketing research, 18(1), 39-50.

Hair, J. F., Black, W. C., Babin, B. J., Anderson, R. E., \& Tatham, R. L. (2010). Multivariate data analysis: A Global Perspective. Upper Saddle River, NJ: Pearson Prentice Hall.

Hair, J. F., Hult, G. T. M., Ringle, C., \& Sarstedt, M. (2016). A primer on partial least squares structural equation modeling (PLS-SEM). Thousand Oaks, CA: Sage Publications.

Händel, M., Stephan, M., Gläser-Zikuda, M., Kopp, B., Bedenlier, S., \& Ziegler, A. (2020). Digital readiness and its effects on higher education student socio-emotional experiences in the context of COVID-19 pandemic. Journal of Research on Technology in Education. doi:https://doi.org/10.1080/15391523.2020.1846147

Hasan, H., Linger, H., Chen, A., Lu, Y., \& Wang, B. (2016). Enhancing perceived enjoyment in social games through social and gaming factors. Information Technology \& People.

Henseler, J., Ringle, C. M., \& Sarstedt, M. (2015). A new criterion for assessing discriminant validity in variance-based structural equation modeling. Journal of the academy of marketing science, 43(1), 115-135.

Hong, A. J., \& Kim, H. J. (2018). College Students' Digital Readiness for Academic Engagement (DRAE) Scale: Scale Development and Validation. The Asia-Pacific Education Researcher, 27(4), 303-312. doi:10.1007/s40299-018-0387-0

Hossain, M. S., Ferdous, S., \& Siddiqee, M. H. (2020). Mass panic during Covid-19 outbreak-A perspective from Bangladesh as a high-risk country. Journal of Biomedical Analytics, 3(2), 1-3.

Hu, L. t., \& Bentler, P. M. (1999). Cutoff criteria for fit indexes in covariance structure analysis: Conventional criteria versus new alternatives. Structural equation modeling: a multidisciplinary journal, 6(1), 1-55.

Huang, R., Liu, D., Tlili, A., Yang, J., \& Wang, H. (2020). Handbook on facilitating flexible learning during educational disruption: The Chinese experience in maintaining undisrupted learning in COVID-19 Outbreak. Beijing: Smart Learning Institute of Beijing Normal University.

Hubbard, R., \& Allen, S. J. (1987). An empirical comparison of alternative methods for principal component extraction. Journal of Business Research, 15(2), 173-190.

Hung, M.-L., Chou, C., Chen, C.-H., \& Own, Z.-Y. (2010). Learner readiness for online learning: Scale development and student perceptions. Computers \& Education, 55(3), 1080-1090.

Hutcheson, G. D., \& Sofroniou, N. (1999). The multivariate social scientist: Introductory statistics using generalized linear models. Thousand Oaks, CA: Sage.

Page $21 / 28$ 
Intrinsic Motivation Inventory (IMI). Retrieved from http://selfdeterminationtheory.org/intrinsic-motivation-inventory/

ITU. (2017). Measuring the information society report 2017: ICT country profiles (Vol. 2). Geneva: International

Telecommunications Union.

Joksimović, S., Gašević, D., Kovanović, V., Riecke, B. E., \& Hatala, M. (2015). Social presence in online discussions as a process predictor of academic performance. Journal of Computer Assisted Learning, 31(6), 638-654.

doi:10.1111/jcal.12107

Kaiser, H. F. (1960). The Application of Electronic Computers to Factor Analysis. Educational and Psychological Measurement, 20(1), 141-151. doi:10.1177/001316446002000116

Kaiser, H. F., \& Rice, J. (1974). Little jiffy, mark IV. Educational and Psychological Measurement, 34(1), 111-117.

Kebritchi, M., Lipschuetz, A., \& Santiague, L. (2017). Issues and challenges for teaching successful online courses in higher education: A literature review. Journal of Educational Technology Systems, 46(1), 4-29.

Khilnani, A., Schulz, J., \& Robinson, L. (2020). The COVID-19 pandemic: new concerns and connections between eHealth and digital inequalities. Journal of Information, Communication and Ethics in Society, 18(3), 393-403. doi:10.1108/JICES-04-2020-0052

Kline, R. B. (2016). Principles and practice of structural equation modeling (4th ed.). New York: The Guilford Press.

Lee, M. K. O., Cheung, C. M. K., \& Chen, Z. (2005). Acceptance of Internet-based learning medium: the role of extrinsic and intrinsic motivation. Information \& Management, 42(8), 1095-1104. doi:https://doi.org/10.1016/j.im.2003.10.007

Lee, Y.-H., Hsiao, C., \& Purnomo, S. H. (2014). An empirical examination of individual and system characteristics on enhancing e-learning acceptance. Australasian Journal of Educational Technology, 30(5).

Lei, P. W., \& Wu, Q. (2007). Introduction to structural equation modeling: Issues and practical considerations. Educational Measurement: issues and practice, 26(3), 33-43.

Levesque, C., Zuehlke, A. N., Stanek, L. R., \& Ryan, R. M. (2004). Autonomy and competence in German and American university students: A comparative study based on self-determination theory. Journal of Educational Psychology, 96(1), 68-84.

MacCallum, R. C., Browne, M. W., \& Sugawara, H. M. (1996). Power analysis and determination of sample size for covariance structure modeling. Psychological methods, 1(2), 130-149.

Miglani, A., \& Awadhiya, A. K. (2017). Mobile Learning: Readiness and Perceptions of Teachers of Open Universities of Commonwealth Asia. journal of learning for development, 4(1), 58-71.

Monjur, M. R., \& Hassan, M. Z. (2020). Early phases of COVID-19 management in a low-income country: Bangladesh. Infection Control \& Hospital Epidemiology, 1. doi:doi:10.1017/ice.2020.147

Naji, K. K., Du, X., Tarlochan, F., Ebead, U., Hasan, M. A., \& Al-Ali, A. K. (2020). Engineering students' readiness to transition to emergency online learning in response to COVID-19: Case of Qatar. Eurasia Journal of Mathematics, Science and Technology Education, 16(10).

Neuwirth, L. S., Jović, S., \& Mukherji, B. R. (2020). Reimagining higher education during and post-COVID-19: Challenges and opportunities. Journal of Adult and Continuing Education, 1-16. doi:https://doi.org/10.1177/1477971420947738

Page 22/28 
Pamungkas, D. K. (2019). Comparing Learning Motivation and Student Achievement Using Various Learning Models. Classroom Action Research Journal, 2(2), 64-70.

Pan, Y.-H. (2014). Relationships among teachers' self-efficacy and students' motivation, atmosphere, and satisfaction in physical education. Journal of Teaching in Physical Education, 33(1), 68-92. doi:http://dx.doi.org/10.1123/jtpe.20130069

Peters, M. A., Rizvi, F., McCulloch, G., Gibbs, P., Gorur, R., Hong, M., . . Robertson, S. (2020). Reimagining the new pedagogical possibilities for universities post-Covid-19: An EPAT Collective Project. Educational Philosophy and Theory, 1-44. doi:https://doi.org/10.1080/00131857.2020.1777655

Podsakoff, P. M., \& Organ, D. W. (1986). Self-Reports in Organizational Research: Problems and Prospects. Journal of Management, 12(4), 531-544. doi:10.1177/014920638601200408

Purnomo, S. H., \& Lee, Y.-H. (2013). E-learning adoption in the banking workplace in Indonesia: an empirical study. Information Development, 29(2), 138-153.

Radianti, J., Majchrzak, T. A., Fromm, J., \& Wohlgenannt, I. (2020). A systematic review of immersive virtual reality applications for higher education: Design elements, lessons learned, and research agenda. Computers \& Education, 147, 103778.

Ryan, R. M., \& Deci, E. L. (2000). Self-determination theory and the facilitation of intrinsic motivation, social development, and well-being. American Psychologist, 55(1), 68-78. doi:https://doi.org/10.1037/0003-066X.55.1.68

Sakib, N., Bhuiyan, A. I., Hossain, S., Al Mamun, F., Hosen, I., Abdullah, A. H., . . Hossain, M. (2020). Psychometric validation of the Bangla Fear of COVID-19 Scale: Confirmatory factor analysis and Rasch analysis. International Journal of Mental Health and Addiction. doi:10.1007/s11469-020-00289-x

Schumacker, R. E., \& Lomax, R. G. (2010). A beginner's guide to structural equation modeling (3rd ed.). Mahwah, New Jersey: Lawrence Erlbaum Associates.

Sedgwick, P. (2013). Convenience sampling. Bmj, 347:f6304. doi:https://doi.org/10.1136/bmj.f6304

Siron, Y., Wibowo, A., \& Narmaditya, B. S. (2020). Factors affecting the adoption of e-learning in Indonesia: Lesson from Covid-19. JOTSE: Journal of Technology and Science Education, 10(2), 282-295.

Thurstone, L. L. (1931). The Measurement of Social Attitudes. The journal of abnormal and social psychology, 26(3), 249-169. doi:http://dx.doi.org/10.1037/h0070363

Twenge, J. M., Spitzberg, B. H., \& Campbell, W. K. (2019). Less in-person social interaction with peers among U.S. adolescents in the 21 st century and links to loneliness. Journal of Social and Personal Relationships, 36(6), 1892-1913. doi:10.1177/0265407519836170

Wang, Z., \& Tang, K. (2020). Combating COVID-19: health equity matters. Nature Medicine, 26(4), 458-458. doi:https://doi.org/10.1038/s41591-020-0823-6

Watkins, M. W. (2000). Monte Carlo PCA for parallel analysis [computer software]. State College, PA: Ed \& Psych Associates, 432-442.

Xie, K., Debacker, T. K., \& Ferguson, C. (2006). Extending the traditional classroom through online discussion: The role of student motivation. Journal of educational computing research, 34(1), 67-89. 
Xiong, Y., So, H.-J., \& Toh, Y. (2015). Assessing learners' perceived readiness for computer-supported collaborative learning (CSCL): A study on initial development and validation. Journal of Computing in Higher Education, 27(3), 215239.

Yeasmin, S., Banik, R., Hossain, S., Hossain, M. N., Mahumud, R., Salma, N., \& Hossain, M. M. (2020). Impact of COVID19 pandemic on the mental health of children in Bangladesh: A cross-sectional study. Children and Youth Services Review, 117, 105277. doi:https://doi.org/10.1016/j.childyouth.2020.105277

Yu, T. (2018). Examining Construct Validity of the Student Online Learning Readiness (SOLR) Instrument Using Confirmatory Factor Analysis. Online Learning, 22(4), 277-288.

Yu, T., \& Richardson, J. C. (2015). An exploratory factor analysis and reliability analysis of the student online learning readiness (SOLR) instrument. Online Learning, 19(5), 120-141.

Zwick, W. R., \& Velicer, W. F. (1986). Comparison of five rules for determining the number of components to retain. Psychological bulletin, 99(3), 432-442.

\title{
Appendix A
}

\section{Appendix A}

\section{The initial 'Student Online Learning Readiness' Survey}

\author{
A. Motivation
}




\begin{tabular}{|c|c|}
\hline Sub-constructs & Items \\
\hline \multirow[t]{7}{*}{ Interest } & MI1. I think I enjoy learning very much in online environment. \\
\hline & MI2. I think learning in online environment is a boring activity*. \\
\hline & MI3. I would describe learning activity in online environment as very interesting. \\
\hline & MI4. I think online learning activity is quite enjoyable. \\
\hline & MI5. I am open to accept the online environment for my learning. \\
\hline & MI6. I like to work with my classmates in an online environment. \\
\hline & MI7. I like to work with my teachers in an online environment. \\
\hline \multirow[t]{7}{*}{ Perceived Usefulness } & MU1. I believe it is effective to learn in online classes. \\
\hline & MU2. I believe online classes can help my learning. \\
\hline & $\begin{array}{l}\text { MU3. I believe online classes help me to learn more complex topics than face-to-face } \\
\text { classroom. }\end{array}$ \\
\hline & $\begin{array}{l}\text { MU4. I believe online classes allow many opportunities for discussion and sharing ideas } \\
\text { among my classmates. }\end{array}$ \\
\hline & MU5. I would be willing to learn in online classes again because it has some value to me. \\
\hline & MU6. I think online learning is important because it can improve my learning. \\
\hline & MU7. I believe online learning activity could be beneficial to me. \\
\hline \multirow[t]{4}{*}{ Reinforcement } & MR1. Through online classes, I hope to achieve a good grade for the courses I attend. \\
\hline & $\begin{array}{l}\text { MR2. I hope my teachers and classmates will praise me if I can perform good in online } \\
\text { classes. }\end{array}$ \\
\hline & MR3. I hope my attendance in online classes will improve my course grade. \\
\hline & MR4. I hope online classes will have a positive impact in my career. \\
\hline \multirow[t]{8}{*}{$\begin{array}{l}\text { Connectedness/ } \\
\text { Relatedness }\end{array}$} & $\begin{array}{l}\text { MC1. I like to connect with my teachers and classmates in the online learning } \\
\text { environment. }\end{array}$ \\
\hline & MC2. I feel like I can trust my teachers in the online learning environment. \\
\hline & $\begin{array}{l}\text { MC3. I prefer not to interact with my teachers and classmates in the online learning } \\
\text { environment in future*. }\end{array}$ \\
\hline & $\begin{array}{l}\text { MC4. I feel disconnected from my teachers and classmates in the online learning } \\
\text { environment*. }\end{array}$ \\
\hline & MC5. I feel close to my teachers and classmates in the online learning environment. \\
\hline & $\begin{array}{l}\text { MC6. I feel I could develop friendship with my teachers and other students in the online } \\
\text { learning environment. }\end{array}$ \\
\hline & $\begin{array}{l}\text { MC7. I would like to interact with my teachers and classmates more often in the online } \\
\text { learning environment. }\end{array}$ \\
\hline & $\begin{array}{l}\text { MC8. I feel I could develop a good bonding with others through online learning } \\
\text { environment. }\end{array}$ \\
\hline
\end{tabular}

*/tem needs reverse coding

\section{B. Self-efficacy}


Technology

Competency

Social Competency

\section{Situational Factors}

TC1. I feel confident in performing the basic functions of technology used in online learning.

TC2. I feel confident in my knowledge and skills of how to manage software for online learning.

TC3. I feel confident in using the internet to find or gather relevant information for learning.

TC4. I feel competent at integrating computer technologies into my learning activities.

SC1. I feel confident to ask questions to my teachers in online classes.

SC2. I feel confident to seek help from my teachers when needed.

SC3. I feel confident to timely inform my teachers when unexpected situations arise.

SC4. I feel confident to express my opinions to teachers respectfully.

SC5. I feel confident to initiate discussions with my teachers in online environment.

SC6. I feel confident to respect other students' social actions in online environment.

SC7. I feel confident to apply different social interaction skills depending on situations.

SC8. I feel confident to initiate social interaction with classmates.

SC9. I feel confident to work in groups in online environment.

SC10. I feel confident to develop friendship with my classmates in online environment.

\begin{abstract}
Learning atmosphere LA1. I think my living environment is supportive to study in online environment.
LA2. I think I can effectively study from my living place.

LA3. I think my family members around me are helpful for my online study.

LA4. I think it is difficult to study online from the place where I am living*.

Institutional Support IS1. I believe my institution is supportive for my online study.

IS2. I believe I can get the necessary help from my institution to study online.

IS3. I believe my institution makes necessary arrangements for effective online learning.

IS4. I believe my institution can provide a favorable environment for my online study.

Digital access DA1. I believe I have the necessary devices to participate in online classes.

DA2. I believe I can afford the cost of internet to participate in online classes.

DA3. I believe the internet connection and speed is reliable enough for the online classes.

DA4. I think I do not have enough resources to study online*.
\end{abstract}

\section{Figures}




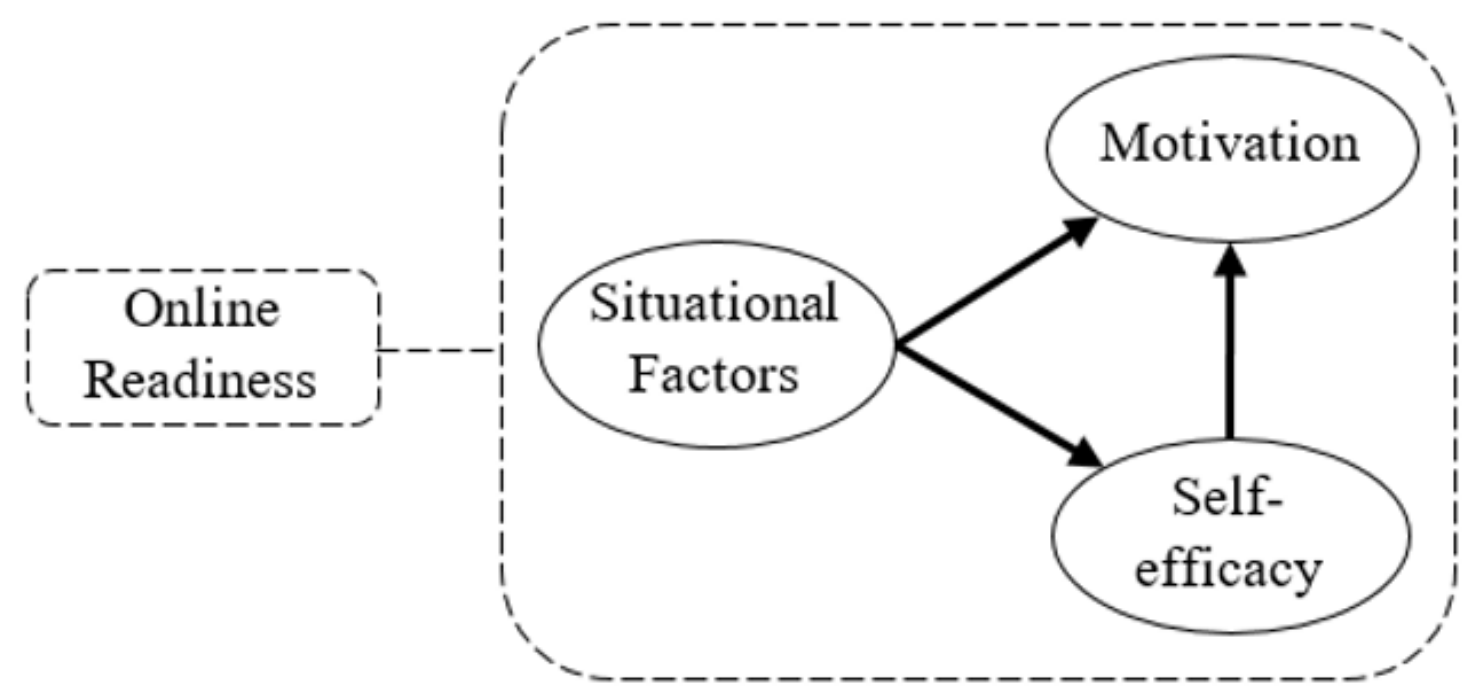

Figure 1

Reconceptualised model for students' online readiness for emergency like COVID-19

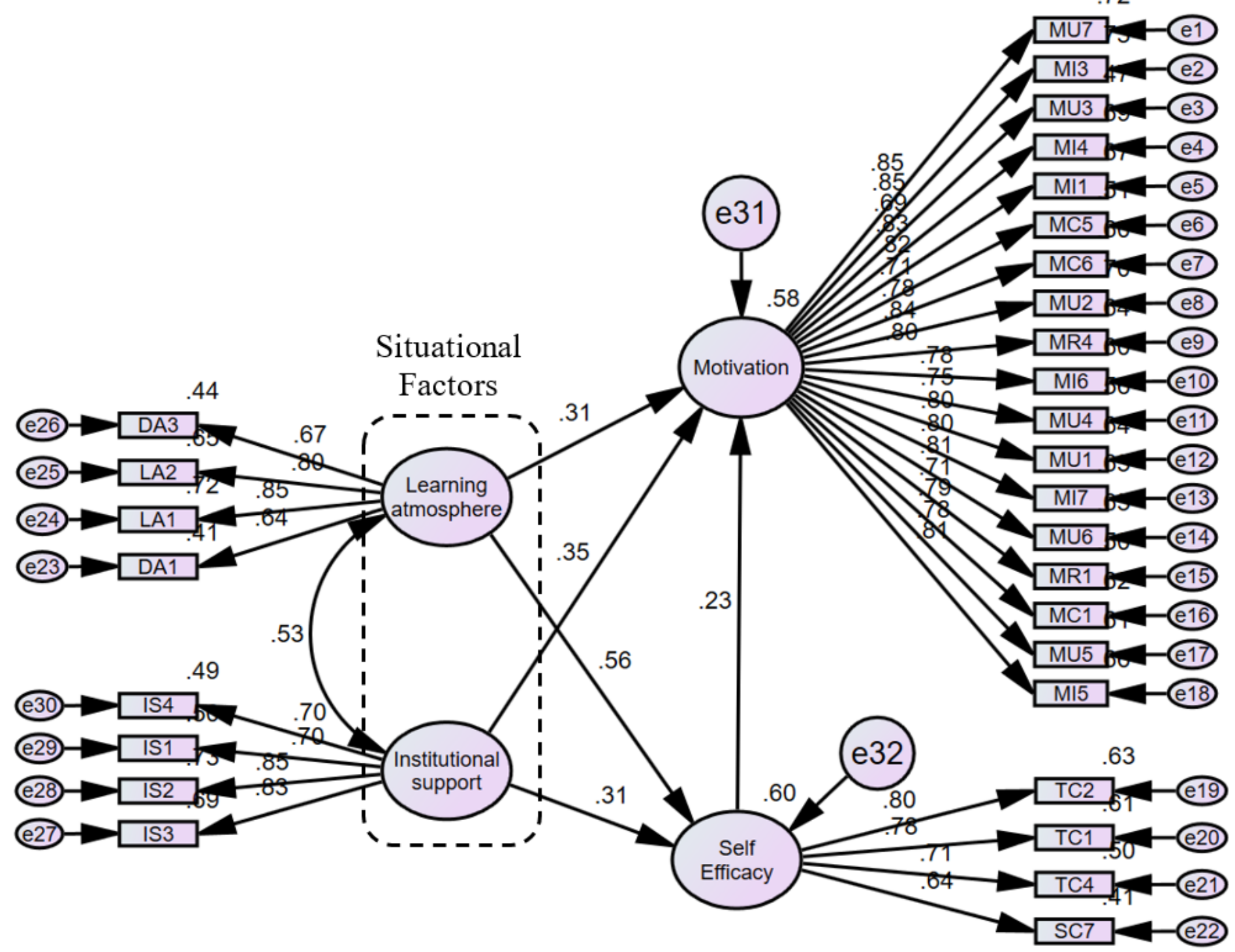




\section{Figure 2}

Final model of students' readiness for online learning with standardized regression weights

Internet connection types

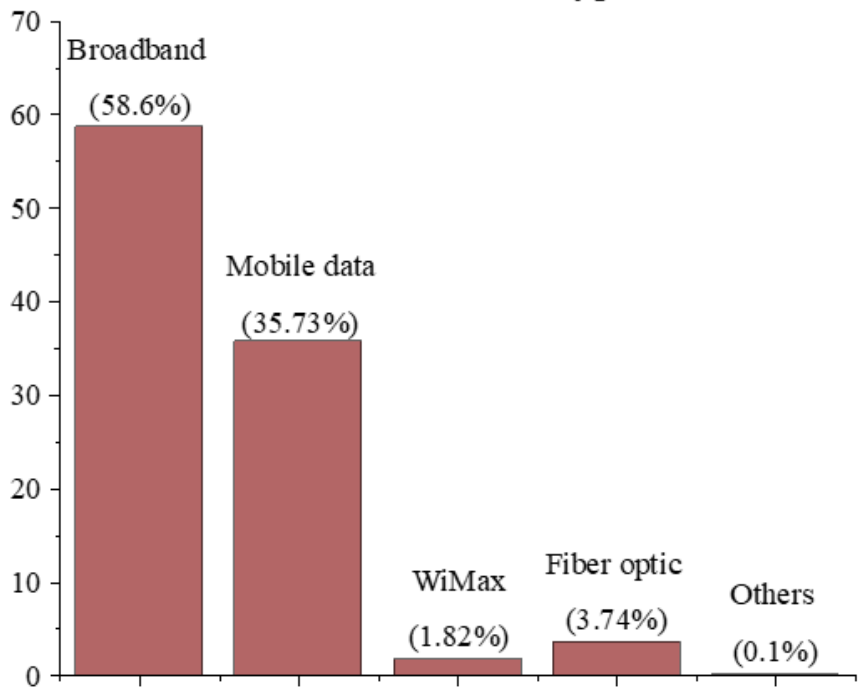

a)
Preferable format for online classes

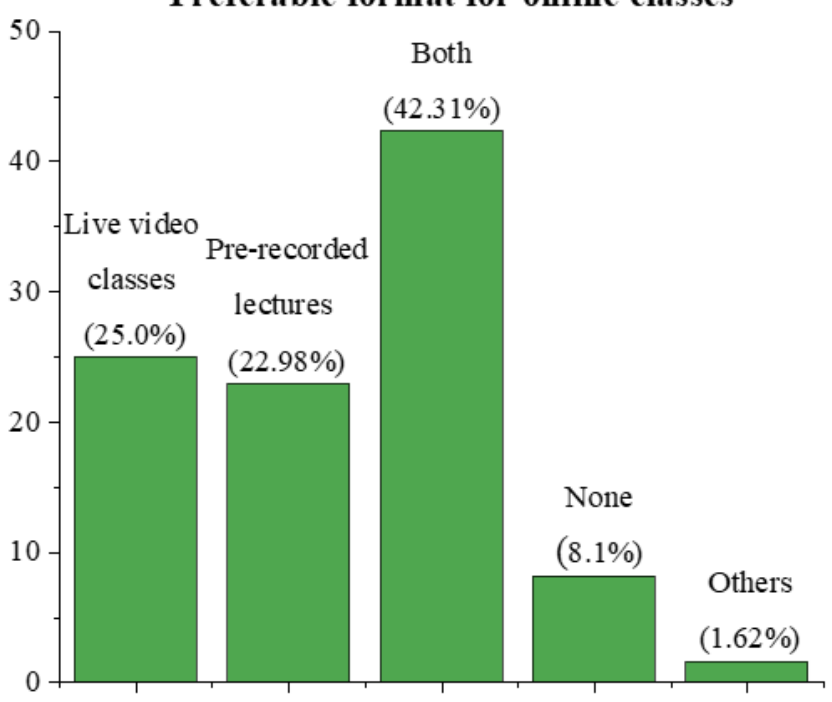

b)

\section{Figure 3}

a) Available internet connection during pandemic; b) Students' preferable mode of online classes during pandemic 